\title{
Le jongleur par lui-même. Choix de dits et de fabliaux, présenté par Willem Noomen
}

\section{Giuseppe Noto}

\section{Q OpenEdition}

1 Journals

\section{Edizione digitale}

URL: http://journals.openedition.org/studifrancesi/35672

DOI: $10.4000 /$ studifrancesi.35672

ISSN: 2421-5856

\section{Editore}

Rosenberg \& Sellier

\section{Edizione cartacea}

Data di pubblicazione: 1 juillet 2005

Paginazione: 130

ISSN: 0039-2944

\section{Notizia bibliografica digitale}

Giuseppe Noto, «Le jongleur par lui-même. Choix de dits et de fabliaux, présenté par Willem Noomen», Studi Francesi [Online], 145 (XLIX | I) | 2005, online dal 30 novembre 2015, consultato il 18 avril 2021 URL: http://journals.openedition.org/studifrancesi/35672 ; DOI: https://doi.org/10.4000/studifrancesi. 35672

Questo documento è stato generato automaticamente il 18 avril 2021.

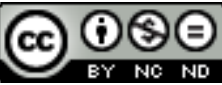

Studi Francesi è distribuita con Licenza Creative Commons Attribuzione - Non commerciale - Non opere derivate 4.0 Internazionale. 


\title{
Le jongleur par lui-même. Choix de dits et de fabliaux, présenté par Willem Noomen
}

\author{
Giuseppe Noto
}

\section{NOTIZIA}

Le jongleur par lui-même. Choix de dits et de fabliaux, présenté par Willem Noomen, LouvainParis, Peeters («Ktemata», 17), 2003, pp. VI + 367.

1 Come indicato nell'“Avertissement" (p. v), il volume si propone di prendere in considerazione, nell'àmbito della cosiddetta 'letteratura giullaresca', in particolare alcuni testi che rappresentano, per così dire, l'autocoscienza' del jongleur, ovvero $\mathrm{i}$ fabliaux in cui il giullare appare come personaggio e i dits che del professionista del divertissement riflettono le inclinazioni.

2 Si tratta di un bell'esempio di quella produzione, destinata prevalentemente ad un pubblico di studenti universitari o di amateurs colti, e capace di muoversi con maestria tra divulgazione e rigore scientifico, che è tipica di molte tradizioni europee e che purtroppo spesso latita in Italia. Nell'"Introduction" (pp. 1-16) il curatore traccia un sintetico ma esaustivo quadro delle acquisizioni critico-storiografiche sulla sfuggente figura del joculator medievale e sui generi del dit e del fabliau, prendendo le mosse dall'ormai quasi centenaria ma tuttora insostituita opera di Edmond Faral su Les jongleurs en France au moyen âge (Paris 1910) e utilizzando una bibliografia notevolmente vasta (anche se incompleta di alcuni items soprattutto di studiosi italiani). Viene poi proposta l'edizione dei dits e dei fabliaux antologizzati, fondata per i testi tràditi da un solo testimone su un'interpretativa che si limita alla correzione degli errori evidenti e per quelli trasmessi da più codici sulla scelta di un manoscritto base (criterio ecdotico a mio avviso condivisibile se applicato a questa particolare tipologia di testi). Ogni singola pièce è preceduta da una nota critica (concernente la tradizione manoscritta, le 
edizioni precedenti, i principali studi critici, le fondamentali caratteristiche formali e contenutistiche) e accompagnata, a fronte, da una traduzione, per cosi dire, 'di servizio' e, a piè di pagina, da un commento a due fasce: la prima costituisce l'apparato propriamente critico, la seconda è dedicata ad osservazioni di carattere variamente esegetico.

3 I dits ed i fabliaux inseriti nello Choix sono i seguenti (secondo la grafia utilizzata nei titoli dei capitoli dedicati ai singoli testi): «Deus bordeors ribauz» (pp. 25-65); «Le Dit des fevres» (pp. 67-85); «Le Jongleur d'Ely et le roi d'Angleterre» (pp. 86-113); «Le Dit de la dent» (pp. 114-127); «Le honteus menestrel» (pp. 129-139); «Les Taboureurs» (pp. 141-151); «Saint Pierre et le jongleur» (pp. 152-185); «Les Putains et les lecheors» (pp. 187-193); «Charlot le Juif» (pp. 194-205); «Les trois boçus» (pp. 206-227); «Les trois chanoinesses de Couloigne» (pp. 228-243); «Boivin de Provins» (pp. 244-275); «Jouglet» (pp. 276-311); «Le vilain au buffet» (pp. 312-335); «Le Foteor» (pp. 337-365).

Da sottolineare che, se per i fabliaux il curatore riprende, con leggere modifiche, l'edizione presente nel NRCF (il Nouveau recueil complet des fabliaux curato dallo stesso Noomen insieme a Nico van den Boogard e uscito in 10 volumi tra il 1983 ed il 1998 per i tipi di Van Gorcum, Assen), per i dits il volume qui presentato ha il merito di dedicare nuove cure ecdotiche ed esegetiche ad opere da tempo (a volte da più di un secolo) neglette dalla critica. 